\title{
Two-year Sealant Survival in a High Caries Cohort at a Graduate Pedodontic Clinic
} \author{
KOREA. \\ Correspondence: \\ B-404 Meet-You-All Tower, \\ Songdo TechnoPark, 7-50, \\ Songdo-Dong, Inchon, \\ 406-840, SOUTH KOREA \\ E-mail: ziyad.haidar@unidds.com
}

Suad A Samara ${ }^{1}$, Ziyad S Haidar ${ }^{2}$.

${ }^{1}$ DDS, MSc (Pedo), Pedodontist, Private Practice, Faculty of Dentistry, University of Aleppo, Aleppo, SYRIA

${ }^{2}$ DDS, Cert Implantol, MSc (OMFS), MBA, PhD, Assistant Professor (US) and Scientific Director (KR). Department of Bioengineering, University of Utah, Salt Lake, UT, USA. Utah-Inha DDS and Advanced Therapeutics Research Center, Inchon, SOUTH

\begin{abstract}
Objectives: To assess the efficacy of resin sealants in children aged 6-12 years referred to one graduate pedodontic program located in the Middle East (2009-2010).

Study Design: Data from a cohort of 110 patients with at least 2 erupted first permanent molars were included in this study. Dental health status was evaluated using the DMFs/t index. UltraSeal XT® Plus sealants ( $\mathrm{n}=253$ applications) were performed in presence of rubber dam isolation and survival carefully inspected and scored at 1 and 2 years. Cross-sectional examination of descriptives and bi/multivariate analysis followed.

Results: Majority (63\%) were males. Caries were diagnosed in $77.9 \%$ of children with only $1 \%$ deemed caries-free. Hence, mean DMFs/t was 9.3 $\pm 6.1 / 7.2 \pm 5.1$, respectively. At 2 years, $66 \%$ of sealants were completely retained and $11 \%$ completely lost. Analysis revealed higher sealant survival in mandibular teeth.

Conclusions: Fluoride-releasing resin sealant is an effectual preventive tool especially in such a high carious population.
\end{abstract}

Key Words: Dental Caries, Pit and Fissure, Prevention, Retention, Resin, Sealant, Syria. 


\section{Introduction}

Dental caries can be described as a chronic, multi-factorial, diet-induced and non-infectious disease that continues to pose a social, political, behavioral, medical and dental problem with endemic proportions not limited anymore, despite popular belief, to only a few developing countries. For a long time, the prevalence of tooth decay has been constantly shown and proudly reported to decline in developed countries around the World, until Bagramian et al., revealed reality, in 2009 (1). An epidemiological perspective and call for immediate action were based on a marked global increase in dental caries signaling a still-pending public health crisis with serious impact on the future of oral health care, dental professional practices, patient accessibility to services and the general well-being of the global community. If in a well-developed nation such as the United States, dental caries continue to be a more common chronic childhood disease than asthma and hay fever (2), how would one expect the severity of such a public health problem be represented in other less-developed and disadvantaged countries? For instance, in a relatively rich country such as the Kingdom of Saudi Arabia where medical insurance and dental coverage might not pose an obstacle from oral health care, it has been reported that the prevalence of dental caries continues to increase in pre-school as well as school-aged children. Al-Malik and Rehbini reported soon after inclining caries prevalence rates than other similar earlier studies in Saudi cities with a dmfs/t of $23.18 \pm 15.64 / 8.06 \pm 4.04$, respectively (3). Further, the authors expected that the level of decay in permanent teeth will continue to increase, despite the school and public health programs offering systemic and topical fluorides, toothpastes, oral health education to families and so on. In less fortunate regional area, the Palestinian West Bank, for example, a mean $\mathrm{dmft}$ score of 6.5 in the school-aged children population was recently reported, calling for an urgent need of immediate public health programs (1). Likewise, it has been reported earlier that the high caries risk and experience in many Middle Eastern states was comparable to that in industrialized nations due to the relatively increased consumption of refined sugars and soft drinks $(4,5)$, mainly imported and adapted from Western dietary habits. Furthermore, such rates are expected to increase even faster in some Arab countries, such as Syria and Lebanon were oral health care systems suffer from inequality due to a strong socioeconomic, political and environmental factors interplay, to note a few. In 2003, Taifour et al. $(7,8)$ questioned how would children living in such countries with less-fortunate oral health systems (in terms of governmental policies, investment capacities and willingness, etc) benefit from effective preventive measures, if any. In part of the study, they considered a sample of 7.5 years-old Syrian school children and found that the prevalence of caries was $57.6 \%$. Further, they concluded that filled glass ionomer sealant materials seem effective in preventing caries in newly-erupted first molars of such a high-risk population (8). Indeed, pit and fissure sealants have been recommended as a caries-prophylactic regimen for years together with maintaining fine oral hygiene and healthy dietary habits (7-9). Briefly, glass ionomer and composite resin sealants are placed to prevent pit and fissure caries initiation and to arrest caries progression via providing a physical barrier that inhibits micro-organisms and food particles from collecting in those anatomical coronal features. They are commonly effective in recently erupted teeth (8-10), as mentioned earlier. However, success, whether short- or long-term, is highly dependant on the material and technique used. If part or the entire bond between the tooth and the sealant is broken, sealant protection efficacy is either reduced or completely lost. Hence, sealant survival and effectiveness, especially in public programs, has been for decades deemed essential for evaluation of services provided and anticipation of outcomes (11). For example, in 1994, Cooney and Hardwick (12) evaluated in one Canadian pilot study, the retention and benefit of 1631 sealants applied on first and second permanent molars up to 2 years post-eruption. Results showed that $85 \%$ were completely retained, $13 \%$ were partially retained and $2 \%$ subsequently carious or restored. They have also identified that sealant material loss occurred more from the buccal and lingual surfaces of mandibular and maxillary molars, respectively. In an earlier study, Anson et al. (13) examined sealant survival and efficacy retrospectively over a 33-month period in one graduate pedodontic program. At six months, a high failure rate of $4 \%$ was reported and attributed to the poor application technique. By end of the study period, only $67 \%$ of all sealants were completely retained. The aim of the present cross-sectional study is two-fold: (a) to evaluate prevalence, severity and patterns of dental caries in 6-12 years old school children attending a graduate pedodontic clinic in the same area of residence and (b) to assess the efficacy and survival of the implied sealant material (and isolation technique) in terms of retentiveness and caries-prevention over a period of 2 years. This would provide vital information on the efficiency of a part of an ongoing free-of-charge and accessible oral health program. The factors evaluated included age, gender and tooth sealed regarding surfaces (including Carabelli's cusp) and arch, analyzed 1 and 2 years after application.

\section{Material and Methods}

A retrospective cohort of 132 children aged 6 to 12 years were enrolled in the present study and followed over a period starting from January 2009 and ending December 2010. The final sample consisted of 110 children with at least 2 erupted first permanent molars. All children 
were regularly attending the pediatric dentistry clinics at the Faculty of Dentistry of Aleppo University, Aleppo, Syrian Arab Republic. Aleppo is a relatively small community with 1 dental school providing cost-free oral health care services by trainees under supervision. Wellstructured oral examinations are routinely performed on dental chairs under unit light with an explorer and mirror. Full medical and dental histories along with the necessary radiography (panoramic, peri-apicals and bitewings) are also regularly carried out and data documented in patient files. The sealant material used for all applications was a light-cured, thixotropic, fluoride-releasing, Bis-GMA $58 \%$ filled resin (UltraSeal $X^{\circledR}$ plus \# 725, Ultra-dent Products, Inc., UT, USA). The following steps summarize the procedure for applying the sealant material: All teeth were isolated with a rubber dam, cleansed with pumice (using a rubber cup), rinsed well, etched with Ultra-Etch ${ }^{\circledR} 35 \%$ phosphoric acid for 15 seconds, rinsed thoroughly for 15 seconds (full water/air spray), air dried, followed by a PrimaDry ${ }^{\circledR}$ (dental drying and priming agent containing $\sim 99 \%$ ethyl alcohol) application for 5 seconds (alongside moisture-free and oilfree air) before applying the flowable sealant material along the fissures and buccal and lingual pits according to manufacturer's instructions. Finally, a 20-second photopolymerization step was done after which sealed areas were checked using an explorer for full coverage and mechanical retention. All sealant applications and clinical observations were done/collected by two postgraduate students (pedodontics) under the supervision of the attending staff of the Department of Pediatric Dentistry, Faculty of Dentistry, Aleppo University, Aleppo, Syria. For this analytical study, data were obtained from patient files, entered onto a computerized database after examination using IBM $^{\circledR}$ SPSS $^{\circledR}$ (version 19) was done. Data was categorized and Student $t$-test performed to detect differences among groups. Descriptives and bivariate analysis were performed using Pearson's chi-square $\left(\chi^{2}\right)$ or Fisher's Exact tests. Multivariate analysis was carried out using a stepwise multiple logistic regression method that determines independent factors under question while other variables were held constant. Sealant survival and association of caries were examined at one and two years after material application. It is noteworthy that this study did not take into account any data on resealed/ restored teeth.

\section{Results}

The study consisted of a representative cohort of 110 Syrian (Arab) school children residing in the city of Aleppo, the largest and most populous in the Syrian Arab Republic. Typically, patients visit the Faculty of Dentistry because of pain. First and second primary molars as well as first permanent molars are often the most frequently associated with pain. Further, consumption of chocolates, potato chips, sweetened juices and soft drinks are popular among school children (14). This seems significantly predominant in the Arab World as well $(5,15,16)$. The risk factors and social/behavioral determinants for dental caries in young children have been extensively reviewed previously (15-20) closely resembling the observations made in the present population sample over the years. For example, in the aforementioned 2006 study among 5-6 years old children attending both, public and private schools, in the United Arab Emirates (UAE) reported high caries prevalence rates of $76.1 \%$ with an average DMFs index of 10.2. This was associated greatly with older children (more so among males) of less educated mothers and partly with 'junk' food, thus raising voices for an urgent need for novel oral health programs aimed at the treatment of the underlying causes of caries in Emirati youth (5). In a following one-stage cluster sampling of another randomly selected 5-6 years old children in the same Ajman area of the UAE, performed in 2010, the prevalence of dental decay was found to remain constant lingering between

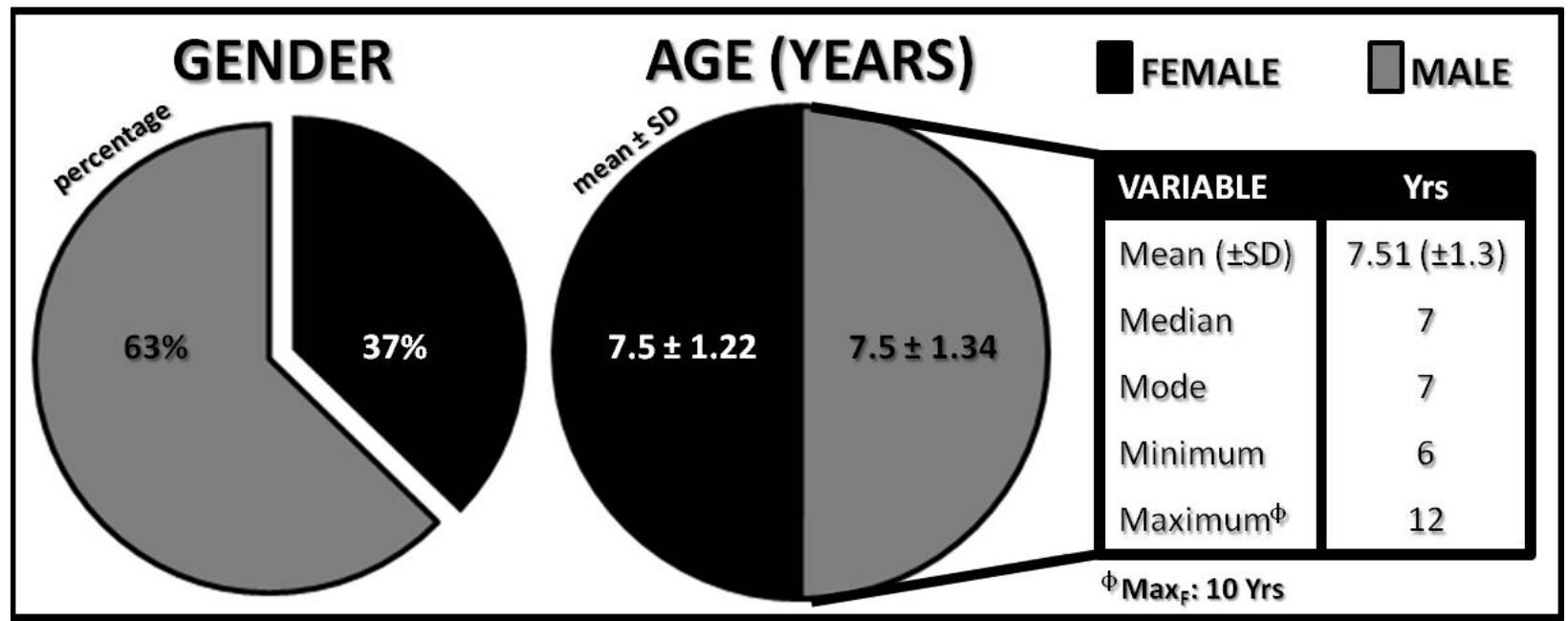

Fig. 1. Descritpives of the 6-12 years old school children sample $(N=110)$ 
$72.9 \%$ and $80.0 \%$. Mandibular molars and maxillary central incisors were found to be the most commonly affected by caries. So, the authors repeated their previous call once more (6).

Caries profile. Figure 1 summarizes the descriptives of the examined 6-12 years old cohort $(\mathrm{N}=110)$. The mean age of children was $7.5 \pm 1.34$ years with the majority being males $(n=69)$. The maximum age of boys was 12 years $(n=2)$ while for girls it was 10 years $(n=4)$. A cross-sectional examination of caries experience (DMFs/t indices) with gender and age was performed and is presented in Table 1 $(a / b)$, respectively. Significant differences $(\rho<0.05)$ were detected between females and males, where as expected, males tend to suffer more of dental decay $(61.5 \%)$. On the other hand, only 1 child (a girl) out of the sample was found to be caries-free (Table 1a). In regards to age, children were grouped accordingly to 2 groups: 6-8 and 9-12 years (Table $1 \mathrm{~b}$ ). Significant differences $(\rho<0.05)$ were detected as well with their DMFt scores were higher scores were notably prevalent in the younger children (6-8 years of age) group with $\sim 69 \%$ of carious teeth, $\sim 9 \%$ of filled teeth and $\sim 8 \%$ of missing teeth due to decay. It is noteworthy to esta- blish that the sample suffers a high-caries rate with a cumulative DMFs/t score of 9.3 $\pm 6.1 / 7.2 \pm 5.1$, respectively. Further, the bulk of children $(n=63)$ lied in the severe caries group $(>8)$. Decay was prevalent in both, posterior $(62 \%)$ and anterior $(38 \%)$ teeth being highest in mandibular $(35 \%)$ molars and premolars than in maxillary $(16 \%)$. UltraSeal $\mathrm{XT}^{\circledR}$ plus sealants were applied to all 110 children (with two or more erupted first permanent molars). Recall visits were then scheduled after 1 and 2 years for post-seal assessment. Patient radiographs were not incorporated in the present look.

Sealant Survival. 253 sealants on caries-free permanent teeth were applied in this study. The distribution of sealed teeth is displayed in Table 2. Sealants were evaluated for retention, coverage and extent of coverage as well as caries. The criteria used to score sealant retention was as follows: Score 1 for completely retained sealant (covering all pits and fissures); Score 2 for partially retained sealant (covering the tooth/tooth is sound); Score 3 for partially retained sealant (covering the tooth/tooth carious); Score 4 for completely lost sealant (tooth sound) and Score 5 for completely lost sealant (tooth carious). This study did not take into account any performed re-

\begin{tabular}{|c|c|c|c|c|c|c|c|c|}
\hline GENDER & \# of Children & Caries-Free & Decayed (D) & \multicolumn{2}{|c|}{ Filled (F) } & \multicolumn{2}{|c|}{ Missing (M) } & DMFs $^{*}$ \\
\hline Female (F) & 41 & $1(2.4 \%)$ & $30.7 \%$ & & $2 \%$ & \multicolumn{2}{|c|}{$4.6 \%$} & $38.5 \%$ \\
\hline Male (M) & 69 & $0(0.0 \%)$ & $47.2 \%$ & & $2 \%$ & \multicolumn{2}{|c|}{$6.1 \%$} & $61.5 \%$ \\
\hline TOTAL & 110 & $1(0.9 \%)$ & $77.9 \%$ & & $.4 \%$ & \multicolumn{2}{|c|}{$10.7 \%$} & $100 \%$ \\
\hline \multicolumn{9}{|c|}{ 'DMFs: significant difference in prevalence of caries and gender detected $(\rho=0.04)$} \\
\hline AGE & \# of Children (F:M) & LOW (1-4) & \multicolumn{2}{|c|}{ MODERATE (4-8) } & \multicolumn{2}{|c|}{ SEVERE (>8) } & TOTAL & DMFt $( \pm S D)$ \\
\hline $6-8$ & $90(33: 56)$ & $7 \%$ & $18 \%$ & & \multirow{2}{*}{\multicolumn{2}{|c|}{$\begin{array}{l}38 \% \\
19 \%\end{array}$}} & $63 \%$ & $8.4( \pm 6.2)$ \\
\hline $9-12$ & $20(8: 12)$ & $8 \%$ & $10 \%$ & & & & $37 \%$ & $5.9( \pm 4.0)$ \\
\hline TOTAL & 110 & $15 \%$ & $28 \%$ & & \multicolumn{2}{|c|}{$57 \%$} & $100 \%$ & $7.2( \pm 5.1)$ \\
\hline
\end{tabular}

Table 1. Distribution of mean DMFs/t scores categorized by gender and age $(95 \% \mathrm{CI})$

\begin{tabular}{|c|c|c|c|c|c|c|}
\hline \multirow{2}{*}{$\begin{array}{l}\text { RETETNION STATUS } \\
\text { TOTAL TEETH = } 110\end{array}$} & \multicolumn{2}{|c|}{ \# of Children (\%) } & \multicolumn{4}{|c|}{ DISTRIBUTION by TEETH ${ }^{\zeta}: n=253$ Sealants } \\
\hline & Year 1 & Year 2 & $\mathbf{M}_{\text {MAX/MAN }}$ & $\mathbf{P M}_{\text {MAX/MAN }}$ & $\mathbf{I}_{\text {MAX/MAN }}$ & TOTAL \\
\hline Completely Retained & $76(69 \%)$ & $73(66 \%)$ & $102(55 \%)$ & $53(87 \%)$ & $6(86 \%)^{\dagger}$ & $161(64 \%)$ \\
\hline Partially Retained & $23(21 \%)$ & $25(23 \%)$ & $55(30 \%)$ & $5(8 \%)$ & 0 & $60(24 \%)$ \\
\hline Completely Lost & $11(10 \%)$ & $12(11 \%)$ & $28(15 \%)$ & $3(5 \%)$ & $1(14 \%)$ & $32(13 \%)$ \\
\hline TOTAL & $110(100 \%)$ & $110(100 \%)$ & $185(73 \%)$ & $61(24 \%)$ & $7(3 \%)$ & 253 \\
\hline
\end{tabular}

? M: Molars ( $1^{\text {st }}$ and $\left.2^{\text {nd }}\right)$; PM: Premolars ( $1^{\text {st }}$ and $\left.2^{\text {nd }}\right)$; I: Incisors (Central); MAX/MAN: Maxillary/Mandibular

"Incisor distribution: 5 Maxillary and 2 Mandibular sealant applications. Sealant fully lost in Mandibular Incisor

Table 2. Sealant survival analysis (after 1 and 2 years) and distribution by teeth 
sealing or restoration procedures. Cross-sectional examination revealed that $69 \%$ of sealants completely survived after 1 year of application. This decreased slightly to $66 \%$ by the end of the 2 year period. On the other hand, $21 \%$ sealants were partially retained after 1 year in comparison to $23 \%$ after 2 years. Finally, $10 \%$ and $11 \%$ of sealants (11 and 12 out of 110 , respectively) were completely lost after 1 and 2 years, respectively. Most teeth to receive sealant applications were first and second molars of both arches, constituting $73 \%$ of total applied sealants. Incisors were the least teeth to be sealed with only $3 \%(n=7)$ out of which only a single application was lost (mandibular central). Figure 2 dissects this data further, in terms of arch and sealed surfaces of molars. Data reveals that $98 \%$ of sealed molar teeth were mandibular. Further, mandibular occlusal surfaces and maxillary mesio-occlusal (Mo) surfaces received the highest portions of sealant applications with $71 \%$ and $51 \%$, respectively. Bi-variate analysis confirmed these findings. Sealant survival was found to be significantly different by tooth $(\rho<0.05)$ and surface $(\rho<0.03)$ however only slightly different by $\operatorname{arch}(\rho=0.054)$. Examination shows that complete sealant survival seems higher in mandibular teeth (molars). Nonetheless, partial retention and complete loss of sealants were of fewer occurrences in maxillary teeth (molars). However, no significant differences were detected $(\rho>0.05)$. The surface sealed is hence, a stronger predictor of sealant survival where occlusal and buccal surfaces (fissures) were at least three times more $(\mathrm{OR}=3.1)$ likely to retain sealant material than palatal (disto-) pits $(\rho<0.05)$. After controlling for age, gender and arch; occlusal fissures were still at least three times more $(\mathrm{OR}=3.0)$ likely to retain sealants than other surfaces $(\rho<0.05)$. Additionally, this performed multivariate analysis revealed no significant differences in sealant survival in terms of arch $(\rho>0.05)$. Females seem to retain their sealants longer than males $(\rho<0.05)$ and in the younger age groups. Child age at sealant application showed a tendency $(\mathrm{OR}=1.3)$ where the younger the child is at time of sealant application, the longer he/she seems to retain the sealant in situ $(\rho=0.033)$, perhaps indicating the effectiveness of sealant material to prevent caries.

Caries Prevention. Collectively, the pit and fissure sealants applied in this study by graduate trainees seem effective in preventing carious progression where $89 \%$ of teeth (with partially- or completely-lost sealant applications) were found to be caries-free after 2 years of observation. Table 3 summarizes this prevalence data. Cross-sectional examination showed that sealants tend to prevent caries in males (6-7 years old) and females (9-10 years old). Older age at time of sealant application was a significant predictor of caries development $(\rho<0.05)$. on the other hand, although data previously demonstrated partial retention and complete loss of sealants were of fewer occurrences in maxillary teeth (molars), further closer assessment detected that carious partial retention was higher in maxillary molars while carious

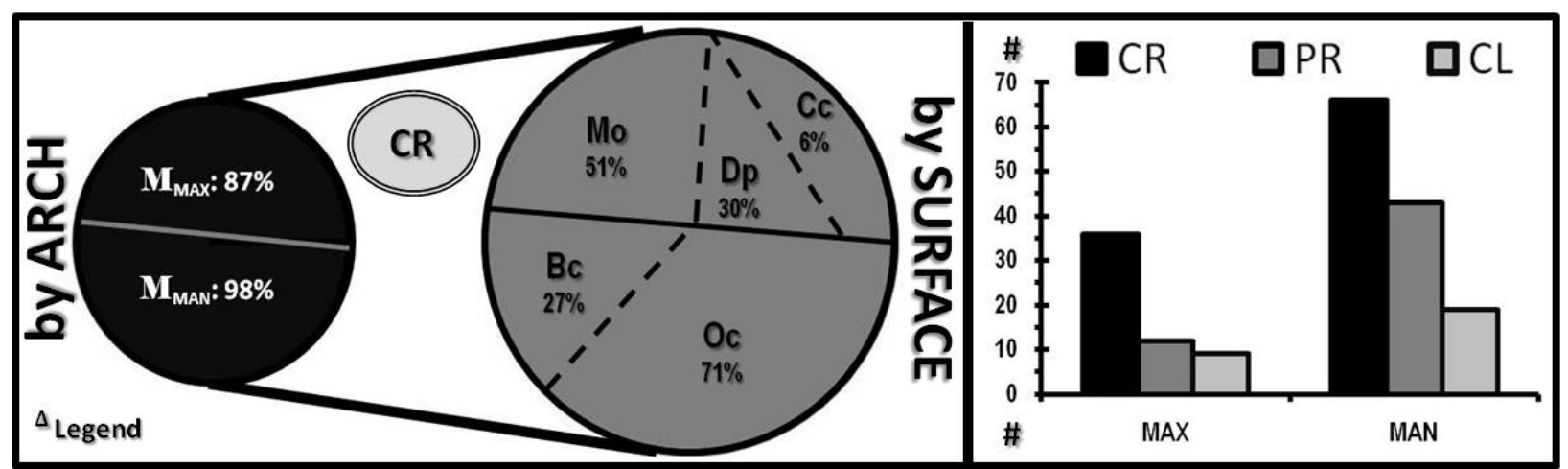

${ }^{\triangle}$ CR: Completely Retained; PR: Partially Retained; CL: Completely Lost; MAX: Maxillary; MAN: Mandibular Mo: Mesio-occlusal; Dp: Disto-palatal; Cc: Carabelli's cusp; Bc: Buccal; Oc: Occlusal (data for $1^{\text {st }}$ Molars)

Fig. 2. Distribution of sealant survival by arch and surface after 2 years of application

\begin{tabular}{|c|c|c|c|c|c|}
\hline \multirow{2}{*}{$\begin{array}{l}\text { SECONDARY CARIES } \\
\text { TOTAL TEETH }=110\end{array}$} & \multicolumn{5}{|c|}{ \# of Children (\%) with carious lesions 2 Years post-sealant placement } \\
\hline & Tooth is Sound & Tooth is Carious & Tooth & GENDER & AGE GROUP \\
\hline Sealant Partially Retained & $24(96 \%)$ & $1(4 \%)$ & $\uparrow \mathbf{M}_{\mathrm{MAX}}$ & $\mathrm{F}>\mathrm{M}$ & $6-8(>7)$ \\
\hline Sealant Completely Lost & $9(75 \%)$ & $3(25 \%)$ & $\uparrow \mathbf{M}_{\text {MAN }}$ & $M>F$ & $9-12(>10)$ \\
\hline
\end{tabular}

${ }^{\ddagger} \uparrow$ signifies higher frequency of retention status in $1^{\text {st }}$ and $2^{\text {nd }}$ Molars (by arch); F: Females; M: Males

Table 3. Prevalence of caries in sealed teeth and distribution by arch, gender and age 
complete loss was mainly in mandibular molars irrespective of gender, age, number of teeth and sealed surfaces $(\rho<0.05)$. Indeed, our multivariate analysis revealed that maxillary teeth were almost two-fold $(\mathrm{OR}=1.7)$ less likely to be carious $(\rho=0.047)$ and teeth with completely lost sealants (mainly mandibular with $19 \%$ in comparison to $9 \%$ for maxillary) were five times more likely to become carious $(\mathrm{OR}=5.2)$. Lastly, occlusal fissures were found to have three times the odds of developing carious lesions if compared to others $(\mathrm{OR}=3.1)$. However, this study did not test the effect of fissure morphology or tooth eruption times.

\section{Discussion}

The purpose of this study was initially to provide data on the caries-related oral health status of young school children visiting a graduate clinical pedodontic program. Then, we examined retrospectively the correlation of this 6-12 years old high-risk cohort with efficacious pit and fissure sealant application by the attending trainees in terms of dental caries progression and sealant survival profiles during a two-year period (2009-2010). As expected, caries prevalence and DMFs/t scores were found to be high among this group of children. More importantly, prevalence did not seem to have changed since 1991 where it was reported in the Syrian capital city, Damascus, to be $65 \%(7,17)$. The decay (D) component was the major portion of the DMFs/t indices indicating (a) a high percentage of un-treated carious lesions and (b) reflecting the high treatment needs in this representative community. Our screening agrees closely with findings of other studies performed in the Middle East region. In Saudi Arabia, for example, a prevalence ranging from $45 \%-89 \%(3,15,21)$ with a carious scores (primary dentition; dmft) of up to 7.2 have been reported previously $(3,15,21)$. In a previous cluster-sampling approach of randomly selected children from the school children of Ajman, UAE, Hashim et al. (5) observed a dental decay prevalence rate as high as $76.1 \%$ and with a dmfs score of 10.2. Although the children were of younger age group, greater severity was reported among the older male children. This study did not look into the socioeconomic status families; however, dental care in this program is provided free-of-charge, as mentioned earlier, suggesting a relationship between low economic levels and high levels of un-treated dental decay. In this society, it can be further explained by levels of awareness and accessibility to dental services. Routine dental check-ups are not a common practice in Syria as it is not in most parts (if not all) of the Arab World $(17,22,23)$. In 2004 , the oral health status in Syria was visited (17). The reviewers analyzed the last 2 decades in order to deduce and suggest proper tactics for what was seen as a status $q u o$ in the high DMFt values irrespective of age. Further, no change in number of un-treated carious cases was no- ted over the span of 20 years, despite the remarkable increase in number of dentists. Associated costs with dental services and lack of community preventive programs were to blame. Unavailability of fluoridated water and affordable fluoridated tooth pastes were then found to be important factors (6). In addition, starting to brush teeth late (especially in boys) might be an aspect as it was reported to be common in other neighboring communities (3, 18-22). Last but not least, establishing the highcaries prevalence in our sample should be translated into an appropriate interventional oral health care plan on both levels, institutional as well as national. This was in fact called for several times before, especially in countries of the Middle East in a way not limited to curative measures $(1,6,17,21-23)$. Education, advanced training in traumatic restorative treatment approaches were suggested; including appropriate sealants $(6,7,16)$. To the best of our knowledge, a huge chunk of the available literature on pit and fissure sealants has been carried out in low-caries populations $(8-12,19)$. Hence, we also aimed to assess the sealant material and techniques followed in our high-carious sample. This has been as well screened previously in Syria by Taifour and a regional WHO group. However, the study included a younger sample of school children, in the Damascus area and then assessed the 5-year outcome of atraumatic restorative glass ionomer sealants in newly erupted teeth $(7,8)$. In the present study, a resin-based composite material was utilized in a different setting.

From the most commonly utilized co-polymers in dentistry, Bis-GMA (2,2-bis[p-(2'-hydroxy-3'-methacryloxypropoxy)phenyl]propane) is one relatively large epoxy resin-like hybrid with a relatively high water sorption index $(24,25)$. UltraSeal $\mathrm{XT}^{\circledR}$ plus contains a high concentrations of the more rigid structure of BisGMA which would typically result in monomer systems with relatively low degrees of cure and shrinkage which in turn would be expected to lengthen service-life. Glass ionomer sealants have been extensively used as pit and fissure sealants, mainly due to their fluoride-releasing ability which would enhance caries resistance and remineralization (25). It is worth mentioning that the UltraSeal $\mathrm{XT}^{\circledR}$ plus is a fluroride-releasing material and for this reason was deemed the material of choice. Additionally, all sealant applications were performed with a rubber dam in place. Previous consensus on the necessity of moisture control reported the superiority or beneficence of a rubber dam $(20,26,27)$. However, no significant differences were then often noted with simple cotton rolls and suction combination $(10,28)$. Nonetheless, in a recent study in Kuwaiti children, authors showed a 30\% less likelihood of caries in sealed teeth isolated by cotton rolls. Rubber dam isolation was associated with 1.4 times more carious lesions. This was explained by the eruption status of the teeth where a rubber dam requires 
fully-erupted teeth to be placed (10). Hence, the longer times of sealant-free/-less exposure to oral microenvironment lead to caries. This was not very much reflected in our data analysis and perhaps can be explained by the different eruption levels in the sampled cohort. Also, in that study, $\sim 72 \%$ of sealed teeth were placed using a rubber dam, hence, further complementing the reported numbers. Yet, despite the relatively moderate-high success rate of $66 \%$ (for complete retention), our look onto the data concludes an overall satisfactory survival level after 2 years (cumulative $89 \%$ ) of application by two trainees. Our results were better to those reported earlier using glass ionomer sealants (8). In addition, the sealant application regimen followed is simple, userfriendly and time-effective. However, although a routine step, applying a rubber dam in an uncooperative young child has been reported to be time-consuming; traumatic and poor $(10,12,27,28)$. Hence, one would argue that such inferior isolation and moisture control might have contributed to some of the reported findings in patient files, although highly doubtful. Our multivariate analysis revealed that females retained their sealants longer than males and in the younger age groups. Also, child age at sealant application was a success predictor where the younger the child is at time of sealant application, the longer he or she seems to retain the sealant. This might reject the eruption time hypothesis. Further, the calculated odds ratio (OR) at the 2 years time point (with a $95 \%$ confidence level; CI) did not indicate a significant elevated risk (relative risk) between eruption status and sealant retention. Taifour and group reported a 2.1 relative risk implying that unsealed unerupted teeth (first molars) were 2.1 times more likely to fail (caries development) than sealed newly-erupted teeth, after 5 years of follow-up (7). In any case, regardless of the survival and retention rates, the flowable material used seems beneficial in arresting carious development and progression perhaps partly due to the incorporated fluoride release system. This was a retrospective analytical approach and therefore cannot be compared to other recent prospective studies in the literature. Alternatively, in the similar retrospective study highlighted earlier, Anson et al. (13) reported a $67 \%$ success rate after a 33 -month period. Our findings are close. Furthermore, in terms of sealant loss and caries progression, our results were also close to that of Cooney and Hardwick (12) where for example, in the mandibular arch, the caries-susceptible buccal pits had a modest $27 \%$ success rate (complete retention). The authors explained their findings to some extent by the selection of insufficiently erupted teeth, difficulties in isolation and others. We tend to feel the same where eruption levels were not properly acknowledged in the sampled patient files. Additionally, neighboring teeth presence and condition (to sealed teeth) were not fullydocumented. This was too reported earlier. Messer et al.
(29) evaluated the retention of sealants placed in Australian school children during 1989-1994. Similarly herein, the dental files used were not complete and in some instances puzzling and therefore some careful assumptions had to be made. This should be translated directly to improve record keeping guidelines at dental clinics in general and at the host of our study, in particular. In conclusion, suitable proportion of resin sealants was retained over 2 years when compared to other reports from dental schools $(9,11,13,26,27,30)$. Finally, it is noteworthy that mandibular teeth were the most troublesome, thus, requiring improved attention by oral care providers. Yet, pit and fissure sealants remain a simple and effective caries-prevention measure that should be incorporated in any national interventional oral health program targeting young pre-school as well as school children.

\section{Acknowledgment}

The authors thank the graduate dentists and evaluators at the pedodontic clinic, Faculty of Dentistry, Aleppo University. Gratitude goes to VS Joo and TG Ramasamy for proof-reading the manuscript. Statistical analysis of data was supported by funding operating grants provided to the Utah-Inha DDS \& Advanced Therapeutics Research Center, KR.

\section{References}

1. Bagramian RA, Garcia-Godoy F, Volpe AR. The global increase in dental caries. A pending public health crisis. Am J Dent. 2009;22:3-8.

2. McBride DL. A reevaluation of the 2000 Surgeon General's report on America's oral health: opportunities for health care providers. J Pediatr Nurs. 2010;25:441-3.

3. Al-Malik MI, Rehbini YA. Prevalence of dental caries, severity, and pattern in age 6 to 7 -year-old children in a selected community in Saudi Arabia. J Contemp Dent Pract. 2006;7:46-54.

4. Ismail AI, Tanzer JM, Dingle JL. Current trends of sugar consumption in developing societies. Community Dent Oral Epidemiol. 1997;25:438-43.

5. Hashim R, Thomson WM, Ayers KM, Lewsey JD, Awad M. Dental caries experience and use of dental services among preschool children in Ajman, UAE. Int J Paediatr Dent. 2006;16:257-62.

6. Hashim R, Williams SM, Thomson WM, Awad MA. Caries prevalence and intra-oral pattern among young children in Ajman. Community Dent Health. 2010;27:109-13.

7. Taifour D, Frencken JE, Beiruti N, van't Hof MA, Truin GJ. Prevalence of caries and lesions treatable through the ART approach in high caries risk schoolchildren in Damascus, Syria. Med Princ Pract. 2003;12:102-6.

8. Taifour D, Frencken JE, van’t Hof MA, Beiruti N, Truin GJ. Effects of glass ionomer sealants in newly erupted first molars after 5 years: a pilot study. Community Dent Oral Epidemiol. 2003;31:314-9.

9. Aleksejuniene J, Brondani MA, Pattanaporn K, Brukiene V. Best practices for dental sealants in community service-learning. J Dent Educ. 2010;74:951-60.

10. Francis R, Mascarenhas AK, Soparkar P, Al-Mutawaa S. Retention and effectiveness of fissure sealants in Kuwaiti school children. Community Dent Health. 2008;25:211-5.

11. Mascarenhas AK, Moursi AM. Use of fissure sealant retention as an outcome measure in a dental school setting. J Dent Educ. $2001 ; 65: 861-5$. 
12. Cooney PV, Hardwick F. A fissure sealant pilot project in a third party insurance program in Manitoba. J Can Dent Assoc. 1994;60:140-5.

13. Anson RA, Full CA, Wei SH. Retention of pit and fissure sealants placed in a dental school pedodontic clinic: a retrospective study. Pediatr Dent. 1982;4:22-6.

14. Freeman R, Oliver M. Do school break-time policies influence child dental health and snacking behaviours? An evaluation of a primary school programme. Br Dent J. 2009;206:619-25.

15. Amin TT, Al-Abad BM. Oral hygiene practices, dental knowledge, dietary habits and their relation to caries among male primary school children in Al Hassa, Saudi Arabia. Int J Dent Hyg. 2008;6:361-70.

16. Mahmood M, Saleh A, Al-Alawi F, Ahmed F. Health effects of soda drinking in adolescent girls in the United Arab Emirates. J Crit Care. 2008;23:434-40.

17. Beiruti N, van Palenstein Helderman WH. Oral health in Syria. Int Dent J. 2004;54:383-8.

18. Naidoo S, Myburgh N. Nutrition, oral health and the young child. Matern Child Nutr. 2007;3:312-21.

19. Harris R, Nicoll AD, Adair PM, Pine CM. Risk factors for dental caries in young children: a systematic review of the literature. Community Dent Health. 2004;21:71-85.

20. Feigal RJ. The use of pit and fissure sealants. Pediatr Dent. 2002;24:415-22.

21. Khan NB. Treatment needs for dental caries in schoolchildren in Riyadh, Saudi Arabia. A follow up study of the oral health survey. Saudi Med J. 2003;24:1081-6.

22. Doumit M, Doughan B. Oral health in school children in Lebanon. Sante. 2002;12:223-8.

23. Beiruti N. Views on oral health care strategies. East Mediterr Health J. 2005;11:209-16.

24. Tuna EB, Aktoren O, Oshida Y, Gencay K. Elution of residual monomers from dental composite materials. Eur J Paediatr Dent. 2010;11:110-4

25. Sasa I, Donly KJ. Sealants: a review of the materials and utilization. J Calif Dent Assoc. 2010;38:730-4.

26. Simonsen R. Pit and fissure sealant: review of the literature. Pediatr Dent. 2002;24:393-414.

27. Albani F, Ballesio I, Campanella V, Marzo G. Pit and fissure sealants: results at five and ten years. Eur J Paediatr Dent. 2005;6:61-5.

28. Yoon RK, Chussid S. Topical anesthesia for rubber dam clamp placement in sealant placement: comparison of lidocaine/prilocaine gel and benzocaine. Pediatr Dent. 2009;31:377-81.

29. Messer LB, Calache H, Morgan MV. The retention of pit and fissure sealants placed in primary school children by Dental Health Services, Victoria. Aust Dent J. 1997;42:233-9.

30. Redford-Badwal DA, Nainar SM. Assessment of evidence-based dental prophylaxis education in postdoctoral pediatric dentistry programs. J Dent Educ. 2002;66:1044-8. 